Doktorantkinja

\title{
INTERKULTURNA KOMPETENCIJA U NASTAVI STRANIH JEZIKA - PREDLOG ZA METODE I TEHNIKE U NASTAVNOJ PRAKSI
}

U mnogim evropskim obrazovnim sistemima interkulturni model učenja stranih jezika integrisan je u modernu glotodidaktiku, dok se interkulturna komunikativna kompetencija postavlja kao ishod i cilj nastave. Interkulturna komunikativna kompetencija i dalje predstavlja novost u nastavnom procesu. Često se dešava da kulturološki sadržaji u udžbenicima ne bivaju analizirani, a interkulturna komponenta zanemarena prilikom učenja stranog jezika. Ipak, razvoj svesti o polaznoj i ciljnoj kulturi u integrisanom učenju jezika i kulture bitan je iz više razloga i predstavlja važan elemenat svesti i identiteta pojedinca koji se na kraju tako osmišljenog obrazovanja lakše snalazi u multukulturnom društvu. Cilj ovog rada je da objasni i opravda mesto koje interkulturna kompetencija zauzima u savremenoj glotodidaktici i da ponudi predloge za kreativnu primenu metoda unutar i van učionice.

Ključne reči: interkultura, kultura, interkulturna komunikativna kompetencija, strani jezik, glotodidaktika, metode, tehnike

\section{Uvod}

Interkulturno učenje stranih jezika je model koji predlažu Evropska komisija i Unesko i već je integrisan u mnoge evropske obrazovne sisteme. U Republici Srbiji interkulturna kompetencija se pojavljuje kao jedna od ključnih kompetencija u „Opštim standardima postignuća za kraj osnovnog obrazovanja za strani jezik“,

* tijana.gsh@gmail.com 
zvanično utvrđenim 2017. godine („Službeni glasnik RS”, br. 88/2017 od 29.9.2017). Budući da je reč o relativno novom modelu učenja, a usled problema smanjenog fonda časova stranog jezika u školama, neretko se dešava da kulturološki sadržaji ne bivaju obrađeni tokom nastavnog procesa. Ipak, interkulturni pristup nastao je iz savremenih potreba pojedinca da bolje posluje sa pripadnicima drugih kultura i da se bolje integriše u svoje multikulturno društvo. U radu ćemo se kratko ostvrnuti na razvoj interkulturnog modela u nastavi radi uviđanja njegove važnosti. Kao pomoć nastavnicima stranih jezika, nakon analize komponenti interkulturne kompetencije i kulturoloških tema, ponudićemo predloge za pojedine konkretne metode, tehnike i sadržaje koji imaju za cilj stvaranje interkulturnog govornika.

\section{Razvoj interkulturnog pristupa u glotodidaktici}

U ovom poglavlju osvrnućemo se na istorijski razvoj pristupa i metoda u nastavi i učenju stranog jezika radi izdvajanja novina koje interkulturni komunikativni pristup donosi.

Gramatičko-prevodni pristup u nastavi stranih jezika bio je zastupljen tokom XVIII i XIX veka i ugledao se na klasični model učenja korišćen tokom predavanja latinskog i grčkog jezika. On podrazumeva fokus na gramatička pravila, učenje leksema, konjugiranje glagola, dekliniranje imenica i prevođenje rečenica i tekstova. Budući da su komunikativne veštine bile gotovo zanemarene, neretko se dešavalo da se tako naučeni strani jezik mogao koristiti samo receptivno, prevashodno za čitanje tekstova na ciljnom jeziku. Poslednjih decenija XX veka komunikativno orijentisana didaktika preovlađuje kao model nastavnog procesa. Danas je takav pristup nezaobilazan i ima za cilj razvijanje upotrebne vrednosti jezika. Gramatički elementi svakako su neizostavni, ali se u komunikativnoj nastavi glavni akcenat stavlja na uvežbavanje dijaloga iz svakodnevnog života (Knežević 2016: 307-309). Kulturne i interkulturne metode postaju delom glotodidaktike postepeno sa njenim razvojem od gramatičko-prevodnog do komunikativnog pristupa i menjaju se u nekoliko faza. Prvo nastaje lingvokulturologija koja je faktografskog i enciklopedijskog karaktera, te nastavni sadržaji imaju 
za cilj da ponude informacije i znanja iz oblasti istorije, geografije, politike, privrede, umetnosti, sporta, slobodnog vremena i slično. Paralelno sa ranim razvojem komunikativnog pristupa u glotodidaktici, kulturološki sadržaji imaju za cilj da razviju komunikativne sposobnosti kod učenika radi vođenja dijaloga iz svakodnevnice u kontekstu ciljne kulture, pa se u udžbenicima mogu naći sadržaji vezani za kupovinu odeće, naručivanje u restoranu ili traženje informacija na stanici. Treća faza počinje devedesetih godina XX veka, kada je došlo do integrisanja interkulturnog i komunikativnog pristupa zarad sticanja znanja, veština i sposobnosti tumačenja strane kulture. U ranim fazama razvoja kulturnih metoda, pojam kulture u učenju stranih jezika se neretko vezivao za sadržaje visoke kulture, a ne za navike svakodnevnice (Durbaba 2011:48-49).

Jedni od najzaslužnijih istraživača za implementaciju interkulturnog modela u komunikativnu nastavu su Kler Kramš i Majkl Bajram. Kramš predlaže razvoj pristupa pod nazivom lingvokultura na različitim nivoima i u svim aspektima učenja stranog jezika. Budući da su izučavanje kulture i književnosti međusobno nerazdvojivi i istovremeno sastavni deo procesa učenja jezika, ona predlaže kulturološke i književne sadržaje koji će probuditi radoznalost kod učenika i ponuditi nova značenja. Obradom takvih sadržaja učenici će razumeti da su određena tumačenja i uverenja kulturološki uslovljena. Kramš smatra da je prisustvo kulturoloških aluzija u tekstu daleko važnije od samog izbora teme, jer je neophodno pružiti elemente koji će učenici prepoznati kao kulturološki obojene i uspešno porediti sa fenomenima iz polazne kulture (Snaidero 2019: 18).

Konferencija u Daremu, koju su 1986. organizovali Majkl Bajram i Diter Butjes može se smatrati prekretnicom u integrisanju interkulturnog pristupa u komunikativnu nastavu jezika, koja od tada dobija međunarodnu perspektivu i političko-obrazovnu svrhu (Durbaba 2016: 257). Prema mišljenju autora, cilj razvijanja interkulturne kompetencije ogleda se u prevazilaženju monokulturnog modela učenja i etnocentričnih stavova (Butjes i dr. 1991: 3-8). Od devedesetih godina XX veka interkulturno učenje postaje sastavnim delom didaktike stranih jezika. Na tragu novog pristupa, na času stranog jezika od učenika se očekuje da nauče da dekodifikuju sardžaje ciljne kulture i njene vrednosti kako bi ih uporedili 
sa polaznom kulturom, a ne da isključivo prikupljaju informacije o mestima gde se ciljni jezik govori ili samo uvežbavaju i usvajaju veštine verbalne komunikacije. Prema stavovima Kler Kramš i Majkla Bajrama, krajnji ishod takvog učenja jezika jeste stvaranje interkulturnih govornika (intercultural speakers), koji su u stanju da kritički procenjuju i prepoznaju proizvode i fenomene polazne i ciljne kulture, a ne učenika koji imitiraju maternjeg govornika ciljne kulture, zanemarujući sopstvenu (Snaidero 2019: 17).

\section{Interkulturna komunikativna kompetencija}

Interkulturna kompetencija se uopšteno može definisati kao sposobnost komunikacije pojedinca sa pripadnicima različitih društvenih grupa (Bajram i dr. 2002: 15). Konkretnije govoreći, ona omogućava pojedincu da komunicira, ali i da deluje u kulturno različitom socijalnom okruženju. Kao što je napomenuto, potreba za razvijanjem ovog koncepta javila se u drugoj polovini XX veka usled razvoja ekonomske, privredne, trgovinske i sličnih razmena na svetskom nivou, a političke interesne strukture, međunarodne organizacije i korporacije su prve definisale konkretne aspekte ovog ponašanja sa ciljem uspešne komunikacije i realizovanja poslovanja (Durbaba 2016: 275). Primer toga možemo videti i u prvom priručniku iz interkulture koji je napisao Edvard Hol (The Silent Language, 1959) kako bi olakšao službena putovanja američkim diplomatama i pomogao im da izbegnu nesporazume. Hol je bio mišljenja da se kulturna komunikacija uči i uvežbava na treninzima, a jedan od fokusa bilo je usvajanje neverbalnih elemenata komunikacije (Rodžers i dr. 2002: 10-11).

Razvoj interkulturne kompetencije počiva na postulatu opštih pozitivnih vrednosti - „poštovanje, empatija, fleksibilnost, strpljenje, radoznalost, otvorenost, motivacija, smisao za humor, tolerancija na različitost, spremnost na kritičku promenu mišljenja i stava" (Filipović 2008: 90 prema Durbaba 2016: 276). Prilikom upuštanja u interkulturnu komunikaciju, potencijalnu tenziju možemo savladati uzajamnim poštovanjem i dozom radoznalosti. Neki od elemenata interkulturne kompetencije koji sinergično deluju u susretu sa stranom kulturom jesu: 
- svest o sebi kao kulturnom biću,

- svest o uticaju koji polazna kultura vrši na naše mišljenje,

- sposobnost da istražujemo pretpostavke koje utiču na naše ponašanje,

- otvorenost da testiramo drugačiji pogled na svet, mišljenja i rešavanje problema (Most, 2007: 12).

Kao što navodi Andrijević (2016: 122) objašnjavajući Agvadovu definiciju interkulturne kompetencije, „uspešan interkulturni sagovornik ima izgrađene stavove, odlikuje ga zainteresovanost, radoznalost, otvorenost prema drugim kulturama, spremnost da relativizuje vlastite vrednosti i smanji etnocentrizam, prihvati druge kulture $i$ svoju sopstvenu bez predrasuda, kao i sposobnost da uspešno analizira i reaguje u nepredvidljivim komunikativnim situacijama, reši konfliktne situacije i prevaziđe stereotipe i kulturne nesporazume".

U nastavi stranih jezika razvoj interkulturne kompetencije poklapa se sa razvojem komunikativne kompetencije koje zajedno u krajnjoj istanci stvaraju integrisani model interkulturne komunikativne kompetencije. „Zajednički evropski okvir za učenje, nastavu i ocjenjivanje jezika“ (ZEO) postavlja za cilj višejezične obrazovne politike razvijanje sposobnosti interkulturalne medijacije, a ne stvaranje učenika koji poseduje jezičke kompetencije izvornog govornika ciljne kulture. Dakle, kulturni sadržaji treba da budu neizostavni u udžbenicima i treba da se odnose kako na najviše proizvode čovekovih ostvarenja, tako i na kulturu svakodnevnice, to jest, način ishrane, radno vreme, navike, praznike, razonodu i slično. ZEO takođe definiše kao cilj savremene glotodidaktike prevazilaženje stereotipa putem njihovog osvešćivanja tokom nastave, te se u interkulturnoj glotodidaktici podrazumeva obrada sadržaja koji racionalizuju postojanje pozitivnih i negativnih stereotipnih predstava vezanih za ciljnu i polaznu kulturu (Savet Evrope 2003: 110).

Bajram u jednom od najranijih dela nudi opšte smernice koje je potrebno slediti prilikom obrađivanja kulturoloških sadržaja u udžbenicima:

- učenici treba da aktivno učestvuju u različitim interpretacijama o svetu i o fenomenima koji se javljaju u stranoj kulturi, a koje mogu da porede sa odgovarajućim fenomenima u svojoj kulturi, po principima sličnosti i razlika; 
- selekcija sadržaja, posebno na početnim stadijumima, treba da obuhvati i autostereotipe i heterostereotipe obeju kultura u kontaktu;

- učenicima treba da se obezbedi pristup rutinskim obrascima ponašanja kao i svesnim znanjima pripadnika ciljne grupe kako bi se prilagodili njihovom rutinskom ponašanju i aluzivnim elementima komunikacije;

- učenici treba da imaju pristup i mogućnost analize kompleksnih vrednosti i značenja iz polazne i ciljne kulture, koja se mahom manifestuju u kulturnim institucijama i artefaktima, kao na primer književnost, film, istorija, političko ogranizovanje, socijalno staranje, obrazovanje i slično (Bajram 1994: 50).

Ponuđene smernice podrazumevaju postepeno i spiralno napredovanje u obrađivanju sadržaja. Naime, postepenost podrazumeva kretanje od razmišnjanja o stereotipima do uspešne analize najkompleksnijih fenomena književnosti i slično. Spiralna progresija ogleda se u površnom kontaktu sa artefaktima kulture na početku procesa, kako bi se na iste vraćali na višim stadijuma učenja jezika uz kompleksniju analizu. Ove smernice su poslužile za formulisanje analitičkih katergorija nazvanih minimalni sadržaji; u tom okviru moguće je izdvojiti sledeće teme:

- društveni identitet i društvene grupe (pripadnost društvenoj klasi ili nacionalnoj manjini, profesionalni ili regionalni identitet);

- društvena interakcija (verbalna i neverbalna komunikacija u društvenoj interakciji na različitim nivoima prisnosti);

- verovanja i ponašanje (rutinsko ponašanje društvenih grupa; moralna ubeđenja i religijska verovanja koja su sastavni deo rutinskog ponašanja, kao i rutinska ponašanja iz svakodnevnice);

- društveno-političke institucije (struktura vlasti, socijalne aktivnosti; vrednosti i značenja koja predstavljaju);

- $\quad$ socijalizacija i životni ciklus (institucije vezane za socijalizaciju - porodica, škola, radno okruženje, verske organiza- 
cije, vojska, kao i obredi društvene inicijacije prilikom prelaska iz jednog životnog perioda u drugi; autostereotipi);

- nacionalna istorija (istorijska doba i događaji važni za stvaranje nacije i njenog identiteta);

- nacionalna geografija (geografski faktori unutar granica koji su važni za percepciju države iz perspektive njenih državljana; informacije o nacionalnim granicama i promenama granica);

- nacionalna kulturna baština (artefakti koji se doživljavaju kao amblemi nacionalne kutlure i savremeni klasici);

- $\quad$ stereotipi i nacionalni identitet (savremeni i istorijski simboli nacionalnog identiteta i značenje stereotipa vezanih za nacionalni identitet) (ibidem 51-52).

Bajramova dorada pomenutih smernica i minimalnih sadržaja dovodi nas do poznatog modela interkulturne kompetencije podeljenu na pet složenih tzv. znanja (fr. savoirs). Segmenti ovako definisane kompetencije nalaze se u mnogim aktuelnim kurikulumima za učenje stranih jezika. Bajram uvodi sledećih pet kategorija:

znanja (franc. savoirs), koja se odnose na poznavanje verovanja, ponašanja i kulturnih značenja koje dele različite društvene grupe jedne zemlje, kao i na poznavanje interpersonalne interakcije na ličnom i društvenom nivou. Ovakva znanja pomažu u prevazilaženju predrasuda i stereotima i umanjenju nesporazuma u interakciji;

- $\quad$ stavovi (franc. savoir être), koji se zasnivaju na analizi verovanja, vrednosti, ponašanja i drugih kulturnih značenja, kao i na relativizaciju sopstvenih; podrazumevaju pokazivanje znatiželje, otvorenost i spremnost na susret sa nepoznatim;

- veštine interpretiranja (franc. savoir comprendre), koje predstavljaju sposobnost i veštinu da se razume i protumači događaj ili situacija iz druge kulture i poveže sa odgovarajućim elementima sopstvene kulture. One podrazumevaju pronalaženje zajedničkih tačaka ili kontradikcija koje se mogu rešiti, identifikaciju stereotipa i uzroka nesporazuma;

- veštine otkrivanja i interakcije (franc. savoir apprendre) faire), koje se vezuju za veštinu da se bude u interakciji sa 
drugom kulturom i sposobnost da se usvajaju znanja i iskustva koja su joj imanentna. Da bi se usvojilo novo znanje, važno je prepoznati značajne kulturne fenomene, dati im smisao i dovesti uh u vezu sa drugim fenomenima;

- kritička kulturna svest (franc. savoir s'engager), koja predstavlja sposobnost da se kritički promišlja i procenjuje iz različitih perspektiva, kao i da se određeni sadržaj na odgovarajući način produkuje kako unutar maternje tako i unutar ciljne kulture (Bajram 1997: 34 prema Andrijević 2016: 118-119. i Durbaba 2016: 288);

Iz svih navedenih kategorija i modela proizlazi da interkulturna kompetencija sadrži svoju kognitivnu, afektivnu i bihevioralnu komponentu, koja se poklapa u krajnjoj istanci sa tradicionalnim modelom učenja. Čen i Starosta (1996,1998. prema Andrijević 2016: 136) na tom tragu definišu model interkulturne komunikativne kompetencije kao interkulturnu svest (kognitivna komponenta), interkulturnu osetljivost (afektivna komponenta) i interkulturnu umešnost (bihevioralna komponenta). Isto tako, poznazi Benetov model razvoja interkulturne osetljivosti (Benet 1993) može pratiti razvoj interkulturne komunikativne kompetencije prilikom učenja o ciljnoj kulturi, od pretpostavljenog etnocentrizma ka etnorelativizmu, te nastavni proces može biti shvaćen i kao interkulturna senzibilzacija.

\section{Predlog metoda i tehnika za obradu interkulturnih sadržaja}

U ovom poglavlju ponudićemo predloge za konkretnu primenu didaktičkih materijala, metoda i tehnika za koje smatramo da se uspešno mogu koristiti u nastavi koja ima za cilj razvoj interkulturne komunikativne kompetencije. Na osnovu pomenutih tema, modela i komponenti interkulturne kompetencije koje su razvili Bajram i Kramš, pronaći ćemo odgovarajuće sadržaje i aktivnosti koji su konkretno primenljivi na času stranog jezika. Predložićemo pojedine kreativne metode savremene glotodidaktike koje integrisanjem interkulturnog pristupa u komunikativnu nastavu razvijaju 
radoznalost i pozitivne stavove kod učenika prema učenju o ciljnoj kulturi i osvešćuju elemente iz polazne kulture.

Najčešći izvori informacija i materijali za obradu na časovima stranog jezika jesu tekstovi, što obuhvata pisane tekstove, slike, statističke prikaze, audio zapise, video materijale i slično. U savremenoj didaktici preporučuje se upotreba autentičnih književnih tekstova i novinskih članaka koji nude aktuelnu sliku ciljne kulture. Takav didaktizovani tekst može biti korisna aktivnost na času sa ciljem usvajanja pomenutih znanja (savoirs) iz savremene kulturne realnosti. Stečena znanja se potom mogu uspešno porediti sa trenutnim vrednostima iz polazne kulture (savoir comprendre). Pojedini kulturološki sadržaji u udžbenicima nužno vremenom zastarevaju, te je važno da nastavnik omogući učenicima direktan dodir sa ciljnom kulturom pružanjem ažurnih informacija kada god je to moguće. Veština interakcije (savoir apprendre/faire) podrazumeva direktni kontakt sa ciljnom kulturom, te stoga savetujemo razmene učenika i studenata, gostujuća predavanja pripadnika ciljne kulture ili kontakt sa njima putem društvenih mreža. Detaljnije analize kultura, razvijanje veštine otkrivanja i kritičke kulturne svesti (savoir s'engager) moguće je podstaći didaktičkim postupcima na višim nivoima učenja jezika.

Postoje mnoge savremene metode koje su zastupljene u nastavi stranih jezika te mogu uspešno integrisati interkulturni pristup $u$ konkretne aktivnosti. Da bi proces učenja jezika uz razvoj interkulturne kompetencije bio uspešan, neophodno je angažovati i motivisati učenike na saradnju. U nastavku ćemo posebno izdvojiti pojedine tehnike i metode koje smeštaju učenike u centralni položaj u procesu učenja i od njega zahtevaju aktivno učešće, zainteresovanost i autonomiju u istraživanju, kao što su tandemsko učenje, kritičke diskusije i dijalozi, dramatizacija i TBLL. Predložene metode su dobre za razvoj interkulturne kompetencije jer podrazumevaju rad u paru, rad u grupama, projektni rad i korišćenje savremenih tehnologija u učenju i nastavi, te učenici ostaju motivisani u procesu usvajanja i imaju prilike da unutar učionice ispolje svoju kreativnost.

Tandemsko učenje jezika prevashodno pomaže da se jezik što brže nauči uz uzajamnu pomoć dvaju maternjih govornika, a zasni- 
va se na autonomiji i reciprocitetu. Na taj način, izvorni govornici, koji su istovremeno i učenici stranog jezika, ispravljaju jedni drugima greške, zajedno napreduju u učenju, pri čemu njihova komunikacija, za razliku od dijaloga na času stranog jezika, ne oponaša, već jeste autentična interakcija sa izvornim govornicima. Sama činjenica da su pripadnici dveju kultura u kontaktu otvara prostor za kulturološku razmenu i razvoj interkulturne komunikativne kompetencije. Džejn Vudin je 1993. godine osmislila i organizovala modul tandemskog učenja koji je trajao 12 nedelja i podrazumevao saradnju između španskih i britanskih studenata koji su nakon svake diskusije u paru morali da napišu bar jednu stranicu dnevnika sa utiscima. Analizom stranica dnevnika, Vudin je uvidela spontani razvoj interkulturne komunikativne kompetencije. Vršnjaci su najmanje pisali o proizvodima kulture (književnosti, umetnosti, fokloru), nešto više o obrascima ponašanja (običaji, navike, ishrana, stil oblačenja, slobodno vreme), a najviše vremena i prostora posvetili su idejama (ubeđenjima, verovanjima, vrednostima, školskim sistemima, tržištu rada, politici i vladi; Vudin 2001: 190-200).

Jedan od najzastupljenijih modela za obradu interkulturnih sadržaja koji se često nalaze u udžbenicima na kraju lekcije, ali i svih materijala koji tokom same lekcije mogu biti povodom za kratku diskusiju o sličnosti i razlikama u kulturama, jeste postupak didaktizacije kulturoloških sadržaja koji su predložili Bajram i Kramš. On podrazumeva najpre izolovanu analizu pojave u polaznoj i ciljnoj kulturi, zatim poređenje po sličnosti i razlikama, a potom pomeranje perspektive izlaskom u međuprostor sa kojeg je moguće kritički sagledati pojave i situacije i izabrati interkulturno osetljivi način komunikacije (Kramš 1993. i Bajram 1997. prema Durbaba 2016: 78). Na primer, dijalog o naručivanju kafe u uvodnim lekcijama na početnom nivou učenja jezika može biti kulturološki obrađen - od nabrajanja vrsti napitka prisutnih u kafićima i barovima i analize načina naručivanja i ispijanja kafe u jednoj i drugoj kulturi do dramatizacije početnog dijaloga smeštenog u polaznoj, pa u ciljnoj kulturi.

Scensko izvođenje takođe može biti kreativna metoda za razvijanje interkulturne kompetencije, budući da priređivanje tekstova za scenu podrazumeva izmeštanje iz uobičajene perspektive, promišlja- 
nje o ustaljenim vrednostima i detaljniju analizu realnosti. Dramatizacija kao projektni rad može se zasnovati na oponašanju svakodnevnih situacija ili istraživanju potencijalnih problema i kulturoloških šokova koje učenik stranog jezika može doživeti tokom posete stranoj zemlji ciljne kulture. Prilikom pripreme rada, učenici će uz pomoć nastavnika morati da preispitaju poznate situacije i rutinske radnje da bi ih sagledali iz ugla druge kulture. U okviru metoda dramatizacije, moguće je iskoristiti tehniku igre s podelom uloga (role play) ili tehniku globalne simulacije (global simulation), koju predlaže lingvista Fransis Debiser. Globalna simulacija originalno predviđa igru stvaranja lažnog identiteta i objašnjavanja njegovih osobina ličnosti, nakon čega se od učenika očekuje da reaguje na različite situacije u skladu sa karakteristikama izmišljenog lika. Slično tome se mogu dodeliti identiteti različitih kultura u simulaciji na stranom jeziku čiji će okvirni kontekst predložiti predavač. Na primer, učenici se mogu izvinjavati, tražiti uslugu, iskazati nezadovoljstvo, rešiti nesporazum na stranom jeziku kao pripadnici polazne i ciljne kulture koristeći verbalnu i neverbalnu komunikaciju (Snaidero 2019: 37-42).

Jedna od važnih metoda za postizanje samopouzdanja i tečnog izgovora kod učenika stranog jezika je TBLT/TBLL (Task-Based Language Teaching / Task-Based Language Learning), koji se zasniva na zadacima kao aktivnostima, podrazumeva grupni rad i kooperativno učenje. Zadaci koji su delom ovog metoda razvijaju jezičke kompetencije, produbljuju znanja, motivišu učenike, ali ih i pripremaju za život van učionice. Iako se TBLT vezuje isključivo za komunikativnu nastavu, uvođenjem kulturoloških sadržaja za obradu učenici će uspešno integrisati interkulturnu i komunikativnu kompetenciju, što je cilj savremene didaktike stranih jezika. Adelhajd Hu dala je predlog projekta za francuski i španski kao strani jezik kod studenata završnih godina fakulteta na naprednim nivoima poznavanja jezika, ali se adaptiranjem sadržaja njen projekat može primeniti na bilo koji drugi strani jezik i uzrast. Naime, u pripremnoj fazi (pre-task) uvodi teme plurilingvizma, multikulturalizma i identiteta putem pisanih tekstova, filmova i muzike iz ciljnih kultura koji se bave pomenutim temama. U narednoj fazi zadatka (task cycle) studenti sami i uz pomoć predavača nalaze tematski sličnu literaturu u skladu sa svojim 
interesovanjima, a potom prave kratak intervju sa prijateljima, poznanicima ili zaposlenima u obližnjim radnjama koji su emigrirali i usvojili drugi jezik i kulturu, u ovom slučaju nemački. Pored sastavljanja kratkih biografija na stranom jeziku, učenici u završnom delu zadatka (post-task) mogu da naprave primedbe na fenomen preključivanja kodova kod poliglota ili prisustvo žargona u drugom jeziku migranata (Hu 2005. prema Snaidero 2019: 79-82). Iz ovog primera je jasno da se interkulturno mogu promatrati teme koji nisu usko vezane za ciljnu kulturu, već su njome inspirisane ili je reč o globalnim fenomenima. Studenti sa razvijenim veštinama otkrivanja i kritičkom svešću kao krajnjim produktom interkulturnog učenja u stanju su da sa radoznalošću priđu nepoznatim temama i da potaknuti tekstovima iz ciljne kulture revalorizuju polaznu.

\section{Zaključak}

U ovom radu napravili smo kratak pregled razvoja interkulturnog pristupa u nastavi stranih jezika da bismo bolje razumeli važnost koja se interkulturnoj komunikativnoj kompetenciji pridaje u standardima. Analizom komponenti interkulturne komunikativne kompetencije uvideli smo njen značaj za razvoj znanja, stavova, veština, kritičke svesti i kulturološku senzibilizaciju pojedinca. Na osnovu teorijskog okvira istakli smo pojedine savremene metode komunikativne nastave koji integracijom interkulturnog modela mogu da podstaknu učenike da na kreativan način razvijaju svoja jezička i kulturološka znanja i stavove.

\section{LITERATURA}

Andrijević 2016: Андријевић, М. Примена аутентичних материјала у настави Л2 за стицање и развој интеркултурне компетенције (докторска дисертација). Филолошки факултет, Универзитет у Београду, Београд, Република Србија.

Bajram 1994: Byram, M. \& Morgan, Teaching-and-Learning Language-and-Culture. Clevedon: Multilingual Matters. 
Bajram 1997: Byram, M. Teaching and Assessing Intercultural Communicative Competence. Clevedon: Multilingual Matters.

Bajram i dr. 2002: Byram, M, Gribkova, B. \& Starkey H. Developing the Intercultural Dimension in Lanuage Teaching. A Practical Introduction dor Teachers. Strasbourg: Council of Europe, Language Policy Division.

Benet 1993: Bennett, Milton J. Towards ethnorelativism: a developmental model of intercultural sensitivity. In Paige, R. M. (Ed.), Education for the intercultural experience, Yarmouth, Maine: Intercultural Press, 21-71.

Butjes i dr 1991: Buttjes, D. \& Byram M. Meditating Languages and Cultures: Towards an Intercultural Theory of Foreign Language Education. Clevedon: Multilingual Matters.

Čen i Starosta 1996: Chen, G. M. \& Starosta, W. J. Intercultural Communication Competence: A Synthesis. In Burelson B.R. \& Kunkel, A.W. (Eds.), Communication Yearbook 19, London: Sage, 353-383.

Čen i Starosta 1998: Chen, G. M. \& Starosta, W. J. Foundations of Intercultural Communication. Boston: Allyn y Bacon.

Durbaba 2011: Дурбаба, О. Теорија и пракса учења и наставе страних језика. Београд: Завод за уџбенике.

Durbaba 2016: Дурбаба, О. Култура и настава страних језика. Увод у интеркултурну примењену лингвистику. Београд: Филолошки факултет.

Filipović 2008: Filipović, J. Interkulturna komunikativna kompetencija u nastavi i učenju stranih jezika, u: Vučo, J. (ur.), Multidisciplinarnost u nastavi jezika i književnosti, Nikšić: Univerzitet Crne Gore, 87-98.

Hu 2005: Hu, A. (2005). Mehrsprachigkeit und Identität: Ideen für ein aufgabenorientiertes sprachübergreifendes Projekt im Französischund Spanischunterricht der Sekundarstufe II. In: Müller-Hartmann, A. \& Schicker-v, D. (Eds.) Aufgabenorientierung im Fremdsprachenunterricht. Task-Based Language Learning and Teaching. Tübingen: Gunter Narr Verlag, 247-256.

Knežević 2016: Knežević, Č. Komunikativni pristup nastavi stranog jezika nasuprot gramatičko prevodnom metodu, Naučno-stručni časopis Svarog, XII, 307-312.

Kramš 1993: Kramsch, K. Context and Culture in Lanuage Teaching. Oxford/New York: Oxford University Press.

Most 2007: Grupa Most. Vodič za unapređenje interkulturalnog obrazovanja. Beograd: Fond za otvoreno društvo.

Rodžers i dr. 2002: Rogers, E., Hart, W. B. \& Miike, Y. (2002). Edward T. Hall and The History of Intercultural Communication: The United States and Japan, Keio Communication Review, XXIV, 4-26. 
Savet Evrope 2003: Savet Evrope. Zajednički evropski okvir za izučavanje, nastavu i ocjenjivanje jezika. Podgorica: Ministarstvo prosvjete i nauke.

Snaidero 2019: Snaidero, T. Insegnare l'Italia di oggi. Guida a una DIdattica dell'InterCultura italiana. Cercenasco: Marcovalerio.

Vudin 2001: Woodin, J. Tandem Learning as an Intercultural Activity. In Byram, M, Nichols, A. \& Stevens, D. (Eds.), Developing Intercultural Competence in Practice, Clevedon: Multilingual Matters, 190-202.

\section{Tijana Gaši}

\section{LA COMPETENZA INTERCULTURALE NELL'INSEGNAMENTO DELLE LINGUE STRANIERE - UNA PROPOSTA DEI METODI E TECNICHE PER LA PRATICA DELL'INSEGNAMENTO}

\section{Riassunto}

In molti programmi scolastici europei il modello interculturale dell'insegnamento delle lingue straniere è integrato nella moderna glottodidattica, mentre la competenza comunicativa interculturale è prevista come obiettivo dell'apprendimento. La competenza comunicativa interculturale rappresenta ancora una novità nel processo di insegnamento in quanto introdotta di recente nei curricula. Accade spesso che i contenuti culturali nei manuali non vengano elaborati e che l'aspetto interculturale venga trascurato durante l'apprendimento di una lingua straniera. Tuttavia, lo sviluppo della consapevolezza della cultura di partenza e di arrivo nell'apprendimento di lingua e cultura è importante per una serie di ragioni e rappresenta un elemento chiave della coscienza e dell'identità di un individuo, che alla fine del ciclo formativo è più in grado di integrarsi nella società multiculturale. Pertanto, lo scopo di questo lavoro è di spiegare e giustificare l'importanza che la competenza interculturale ha nella glottodidattica contemporanea e di offrire suggerimenti per un'applicazione creativa di tecniche e metodi all'interno della classe, ma anche al di fuori dell'ambito scolastico.

Parole chiave: intercultura, cultura, competenza comunicativa interculturale, lingue straniere, glottodidattica, metodi, tecniche 